\title{
INFLUÊNCIA DA TEMPERATURA E PRECIPITAÇÃO NA INFESTAÇÃO DE MOSCA-NEGRA-DOS-CITROS (Aleurocanthus woglumi) EM PLANTIO DE CITROS
}

\author{
SILVA, Anderson Gonçalves ${ }^{1}$ \\ BOIÇA JUNIOR, Arlindo Leal ${ }^{1}$ \\ FARIAS, Paulo Roberto Silva ${ }^{2}$
}

RESUMO: A citricultura, no estado do Pará, exerce importante papel econômico e social, através de arrecadação de divisas para o estado; além da geração de empregos e aquecimento da economia local. Dentre os principais problemas fitossanitários do estado, a mosca-negra-dos-citros (Aleurocanthus woglumi), destaca-se por acarretar prejuízos que podem comprometer até $80 \%$ da produção. Dessa forma objetivou-se com o presente trabalho avaliar a influência de fatores abióticos (temperatura e precipitação) na infestação natural de moscanegra-dos-citros em plantio de citros no estado do Pará. O trabalho foi desenvolvido de setembro de 2008 a agosto de 2009. Fez-se 12 amostragens avaliando-se a infestação da praga na área experimental. Utilizou-se correlações entre infestação de plantas com presença de mosca negra e ás variáveis precipitação pluviométrica $(\mathrm{mm})$ e temperaturas mínima, média e máxima $\left({ }^{\circ} \mathrm{C}\right)$. Como principais conclusões obtidas destaca-se que a área experimental mostrou-se infestada durante todas as avaliações; a temperatura média mensal $\left({ }^{\circ} \mathrm{C}\right)$ influenciou na regulação da população da praga e chuvas intensas reduziram a infestação da mosca-negra-dos-citros.

Palavras-chave: Mosca negra. Citrus sinensis. Fatores abióticos. Infestação natural.

\section{INFLUENCE OF ABIOTIC FACTORS INFESTATION OF BLACKFLY (Aleurocanthus woglumi) PLANTATION IN CITRUS}

SUMMARY: The citrus industry in the state of Pará, has important economic and social role, by raising foreign currency for the state, besides employment generation and the heating of the local economy. Among the major disease problems of the state, the citrus blackfly (Aleurocanthus woglumi), stands out for causing damages that can compromise up to $80 \%$ of production. Thus the objective was with the present work to evaluate the influence of abiotic factors (temperature and precipitation) in a natural infestation of blackfly in the citrus planting in the state of Pará. The study was conducted from September 2008 to August 2009. Were performed 12 samples by assessing the infestation in the experimental area. Were used correlations between infestation of plants with presence of blackfly and ace variables rainfall $(\mathrm{mm})$ and minimum temperature, average and maximum $\left({ }^{\circ} \mathrm{C}\right)$. As main conclusions, stand out that the experimental area was found to be infested during all assessments, the monthly average temperature $\left({ }^{\circ} \mathrm{C}\right)$ influenced in the regulation of pest population and heavy rain reduced the infestation of blackfly of citrus.

Keywords: Blackfly. Citrus sinensis. Temperature. Precipitation. Natural infestation

\section{INTRODUÇÃO}

A produção nacional de laranja, no ano de 2008, atingiu 18.684,985 toneladas. São Paulo é o maior produtor nacional, com 79,7\% de participação na produção da fruta no País,

\footnotetext{
${ }^{1}$ Departamento de Fitosanidade, Unesp/Jaboticabal, São Paulo-Brasil

${ }^{2}$ Universidade Federal Rural da Amazônia (Ufra). Departamento de Fitosanidade.
} 
onde praticamente toda a matéria-prima é processada e o suco exportado (IBGE, 2009). No entanto, nos últimos anos tem-se observado uma redução na área plantada devido, dentre outros fatores, ao fato de que no estado de São Paulo parte da área reservada aos laranjais foi substituída pela cultura da cana-de-açúcar. A principal forma de expansão canavieira está ocorrendo por meio de arrendamento de terras. De modo que para manter a liderança do mercado está ocorrendo à descentralização da produção paulista, com expansão da citricultura para outros estados da federação (FRANCO, 2008 citado por ROSSATO, 2007).

Dentre estes, destaca-se o estado do Pará onde a citricultura exerce importante papel econômico e social, através da arrecadação de divisas para o estado; além da geração de empregos e aquecimento da economia local. O estado apresenta condições edafoclimáticas favoráveis para o desenvolvimento da citricultura, e, diferentemente de São Paulo, a citricultura na região norte encontra-se livre de doenças que podem inviabilizar o agronegócio citrícola na região sudeste, tais como: o cancro cítrico (Xanthomonas axonopodis pv. citri), a morte súbita dos citros e o greening (Candidatus liberibacter asiaticus e Candidatus liberibacter americanus). Desta forma, a citricultura no estado atingiu índices elevados de crescimento nos últimos dez anos. Com os avanços nesse período, o Pará passou a assumir posição de destaque, como maior produtor da região norte ficando entre os seis maiores produtores de laranja do Brasil. Apresentando $90 \%$ de sua produção exportada para o estado de São Paulo e para o nordeste brasileiro (IBGE, 2009).

Dentre os principais problemas fitossanitários do estado, a mosca-negra-dos-citros, Aleurocanthus woglumi Ashby, 1915 (Hemiptera: Aleyrodidae) destaca-se por acarretar danos diretos e indiretos ás plantas cítricas, além de se constitui praga quarentenária presente ou A2 de alerta máximo, restringindo o comércio com outras regiões livres da praga (MAPA, 2009).

Nativa da Ásia, a mosca-negra-dos-citros apresenta-se amplamente distribuída geograficamente (OLIVEIRA et al.,2001). No Brasil a sua primeira ocorrência foi relatada no estado do Pará, em 16 de maio de 2001, em jardins da cidade de Belém (SILVA, 2005), e hoje já se encontra disseminada por vários estados brasileiros inclusive no estado de São Paulo, principal produtor de citros, onde teve seu primeiro relato em março de 2008 (PENA et al., 2008).

$\mathrm{Na}$ região amazônica a praga encontra condições ideais de desenvolvimento, apresentando ciclo evolutivo bastante rápido (CUNHA, 2003). Cada fêmea coloca dois a três espirais de ovos durante sua vida, que varia de 10 a 14 dias. Sendo que, em cada postura são colocados de 35 a 50 ovos (EPPO, 1997). Sem medidas de controle apropriadas, a praga associada ao fungo fumagina (Capnodium sp.) pode causar perdas sérias a citricultura, com 
uma redução estimada no rendimento de $80 \%$. Quando o ataque severo se dá nas plantas ainda novas ou em fase de mudas, pode levá-las a morte (PARKINSON; SEALES, 2000).

Diversos trabalhos corroboram que os fatores abióticos, dentre elas a precipitação e temperatura podem influenciar na infestação de insetos fitófagos (TRNKAA et al., 2007; BATALDEN et al., 2007). De acordo com Delgado (1943), os fatores mais importantes que influenciam sobre a duração do ciclo de $A$. woglumi são umidade relativa e a distribuição das chuvas. Cunha (2003) cita que na região amazônica o A. woglumi encontra condições de umidade e temperatura ótimas de desenvolvimento e que ventos fortes e chuvas pesadas mostraram-se capazes de desalojar e matar adultos da mosca-negra-dos-citros como observado por Flanders (1969) em trabalho no México.

Dessa forma, por ser uma praga exótica, recém introduzida, faltam conhecimentos básicos para a implementação de um manejo adequado do A. woglumi na região amazônica. Dada a relevância desse inseto sugador objetivou-se com o presente trabalho avaliar a influência de fatores abióticos na infestação natural de mosca-negra-dos-citros em plantio de citros no estado do Pará.

\section{MATERIAL E MÉTODOS}

O presente trabalho foi desenvolvido de setembro de 2008 a agosto de 2009. A área experimental está localizada no município de Capitão Poço, mesorregião do Nordeste Paraense, microrregião do Guamá, distante 200 km de Belém, PA. A Fazenda Santana está compreendida nas coordenadas geográficas: $01^{\circ} 45^{\prime} 15^{\prime \prime}$ de latitude Sul, $47^{\circ} 07^{\prime} 30^{\prime \prime}$ de longitude Oeste de Greenwich (sede da fazenda), apresentando solo do tipo Latossolo Amarelo Álico, textura média, clima tipo Ami, segundo a classificação de Köppen, apresentando os maiores índices de pluviosidade de janeiro a maio e os menores de agosto a novembro.

A área experimental de sistema de plantio de citros é constituída por um pomar de laranjeiras da variedade "Pêra Rio" (Citrus Sinensis Osbeck), enxertadas em limão cravo (Citrus limonia Osbeck), plantadas em espaçamento de 5 x 7m, apresentando sete anos de idade; distribuídas em 32 fileiras, apresentando 44 plantas de citros por linha de plantio, totalizando 1.408 plantas em uma área de $49.280 \mathrm{~m}^{2}$; com densidade de plantio, de 285 laranjeiras por hectare.

Á área experimental recebeu adubação de acordo com análise de solos, considerando ás exigências nutricionais da cultura dos citros. Quanto ao controle de plantas daninhas, esse foi feito através de roçadeira mecânica nas ruas do pomar e com uso de herbicida nas linhas 
de plantio. $\mathrm{Na}$ área experimental não se utilizou inseticida no período das avaliações de $A$. woglumi.

O levantamento populacional de mosca-negra-dos-citros foi realizado em $100 \%$ das laranjeiras (avaliação em varredura), avaliando-se a presença ou ausência de ninfas e/ou adultos vivos de A. woglumi. Observaram-se principalmente brotações novas (onde geralmente são encontrados os adultos) e também a parte abaxial das folhas onde se encontram todas as fases imaturas da praga, anotando-se presença da praga com o número um (1) ou ausência da mesma com o número zero (0), para o presente sistema de produção. Realizou-se 12 amostragens, nas seguintes datas: 18/09/08; 20/10/08; 17/11/08; 13/12/08; 17/01/09; 06/02/09; 25/03/09; 22/04/09; 19/05/09; 26/06/09; 24/07/09 e 16/08/09.

Os dados climáticos médios mensais como precipitação pluviométrica $(\mathrm{mm})$ e temperatura $\left({ }^{\circ} \mathrm{C}\right)$ para o município de Capitão Poço - PA, foram obtidos junto à estação meteorológica da empresa Cítricos do Pará - CITROPAR (Estação meteorológica situada próximo ao local do presente experimento) e apresentam-se, juntamente com o índice de plantas com presença de A. woglumi (\%) na tabela 1.

Tabela 1. Infestação e variáveis climáticas de mosca-negra-dos-citros (A. woglumi) em plantio de citros. Fazenda Santana, Capitão Poço - PA, 2008/2009.

\begin{tabular}{cccccc}
\hline Datas de & $\begin{array}{c}\text { Infestação de } \\
\text { Amostragem }\end{array}$ & \multicolumn{3}{c}{ Temperatura $\left({ }^{\circ}\right.$ C) } & \multicolumn{2}{c}{$\begin{array}{c}\text { Precipitação média } \\
\text { mensal (mm) }\end{array}$} \\
\cline { 3 - 5 } & & Mínima & Média & Máxima & \\
\hline Setembro/2008 & 7 & 22,3 & 28,0 & 33,6 & 26 \\
Outubro/2008 & 40 & 22,2 & 28,1 & 34 & 51 \\
Novembro/2008 & 47 & 22,4 & 28,4 & 34,3 & 46 \\
Dezembro/2008 & 29 & 22,1 & 27,8 & 33,5 & 78 \\
Janeiro/2009 & 31 & 21,5 & 27,8 & 34 & 228 \\
Fevereiro/2009 & 2 & 22,7 & 26,7 & 30,6 & 348 \\
Março/2009 & 3 & 23 & 26,8 & 30,6 & 447 \\
Abril/2009 & 43 & 22,9 & 26,6 & 30,2 & 75 \\
Maio/2009 & 50 & 22,5 & 26,5 & 30,5 & 65 \\
Junho/2009 & 14 & 21,5 & 26,5 & 31,5 & 45 \\
Julho/2009 & 11 & 20,8 & 26,4 & 32 & 37 \\
Agosto/2009 & 21 & 20,8 & 26,8 & 32,8 & 39 \\
\hline
\end{tabular}

Fez-se correlações para analisar o índice de plantas com presença de mosca negra com ás variáveis precipitação pluviométrica $(\mathrm{mm})$ e temperaturas mínima, média e máxima $\left({ }^{\circ} \mathrm{C}\right)$. Para ás análises utilizou-se o programa computacional Statistica $7.0^{\circledR}$ (STATSOFT, 2004). 


\section{RESULTADOS E DISCUSSÃO}

Para os resultados obtidos, observou-se a incidência de mosca-negra-dos-citros em todas as avaliações, com infestações da praga variando de 2 a 50\%. Maio, abril e novembro foram os meses que apresentaram maior índice de plantas com presença da praga com respectivamente 50; 43 e 47\% de infestação. Fevereiro, março e setembro foram os meses que apresentaram resultados inferiores com respectivos 2; 3 e 7\% (Figura 1).

Infestações mais elevadas foram obtidas em estudo realizado por Maia (2008), em plantio de citros na mesma região do presente trabalho. $\mathrm{O}$ estudo mostrou que a densidade populacional de A. woglumi foi maior nos meses de dezembro, janeiro, fevereiro e outubro com média de $90 \%$ da área experimental infestada, apresentando-se menor nos meses de abril, maio, junho e julho com média de $25 \%$ de infestação para os referidos meses citados. A menor infestação encontrada em nosso trabalho pode está associada a reduzida infestação inicial de A. woglumi na área experimental, levando em consideração que para ambos os experimentos não se utilizou qualquer tipo de controle para A. woglumi no período avaliado; além das diferenças quanto a precipitação observada nos diferentes anos estudados.

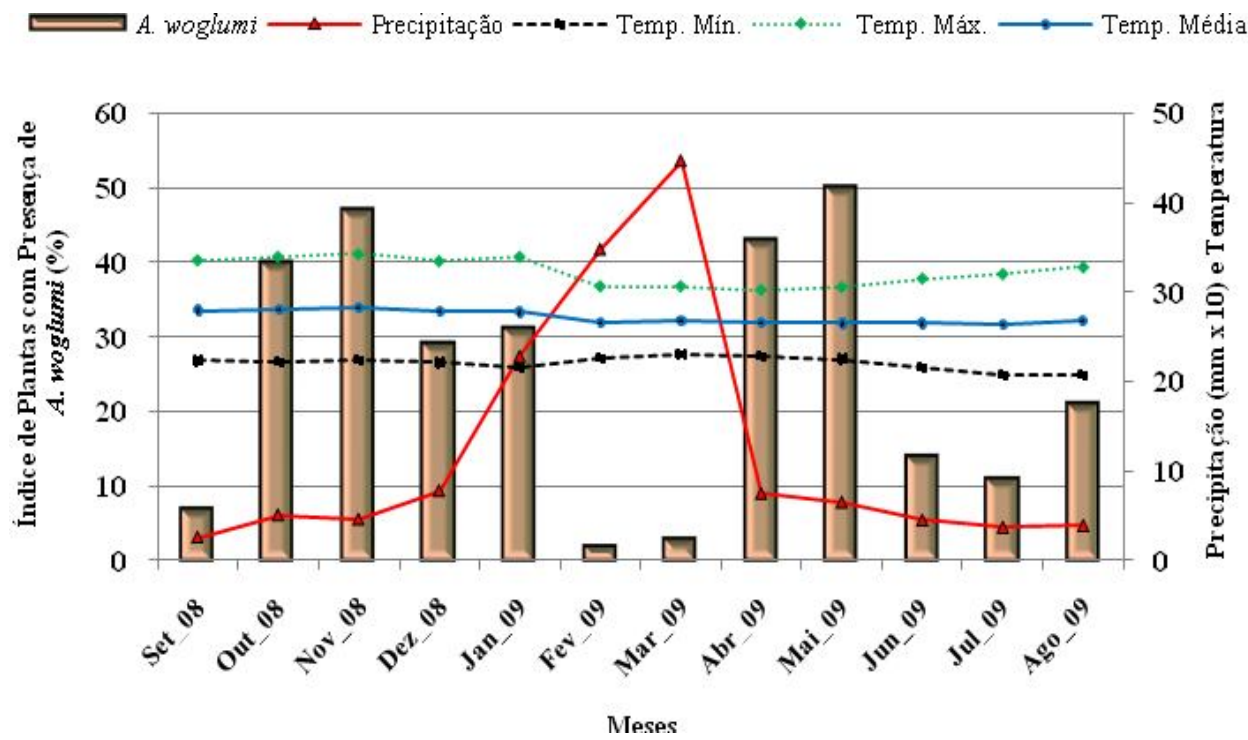

Figura 1. Índice de plantas com presença de mosca-negra-dos-citros (A. woglumi), precipitação pluviométrica acumulada ( $\mathrm{mm}$ x 10) e temperaturas mínima, média e máxima $\left({ }^{\circ} \mathrm{C}\right)$ pomar de citros. Fazenda Santana, Capitão Poço - PA, 2008/2009.

Avaliou-se a influencia dos fatores abióticos na infestação natural de mosca-negrados-citros. A Tabela 2 mostra correlação positiva entre temperatura média e índice de plantas infestadas $\left(\mathrm{r}=0,0,478^{*}\right)$, valor esse significativo a $5 \%$ de probabilidade. Para o presente trabalho a temperatura mostrou-se elevada durante todas as avaliações, condições essas características da região amazônica e tidas como ideais para o desenvolvimento da moscanegra-dos-citros (SILVA, 2005), nessas condições a mosca negra apresenta ciclo evolutivo 
bastante rápido, chegando a apresentar de 5 a 6 gerações anuais (CUNHA, 2003); apresentando sobreposição de gerações, ou seja, em todas ás avaliações foram observados os estágios de ovo, ninfa e adulto de A. woglumi (SILVA, 2005).

Tabela 1: Coeficientes de correlação linear simples (r) entre o índice de plantas com presença de mosca-negra-dos-citros $(A$. woglumi $)$ e temperatura mínima, média e máxima mensal $\left({ }^{\circ} \mathrm{C}\right)$, e precipitação pluviométrica mensal $(\mathrm{mm})$ em plantio de citros. Fazenda Santana, Capitão Poço - PA, 2008/2009.

\begin{tabular}{cc}
\hline Correlação & Coeficientes de Correlação (r) \\
\cline { 2 - 2 } & $\boldsymbol{A .}$ woglumi \\
\hline Infestação x Temperatura Mínima & $0,151^{\mathrm{ns}}$ \\
Infestação x Temperatura Média & $0,478^{*}$ \\
Infestação x Temperatura Máxima & $0,215^{\mathrm{ns}}$ \\
Infestação x Precipitação Média & $-0,474^{\mathrm{ns}}$ \\
\hline
\end{tabular}

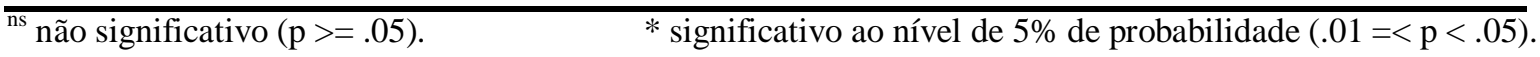

Para os insetos em geral a temperatura é muito importante para o seu desenvolvimento quando o fator alimento não é limitante. No presente trabalho, por se mostrar homogênea na área, a relação entre temperatura e precipitação mostrou-se como principal fator responsável na infestação da mosca-negra-dos-citros na área experimental, o que pode ser bem visualizado através da Figura 1, principalmente para os meses de fevereiro e março, período de maior precipitação, onde houve menor infestação de mosca negra para a área em estudo.

Quanto a precipitação pluviométrica, está apresentou correlações não significativas (Tabela 2). No entanto precipitações elevadas reduziram a infestação da mosca negra como se pode observar na Figura 1.

A influência da precipitação no número de plantas com presença de A. woglumi foi bem nítida nos meses mais chuvosos, principalmente fevereiro e março (348, $447 \mathrm{~mm}$ respectivamente) (Figura 1), com redução drástica da praga na área experimental, apresentando 2 e $3 \%$ de plantas com presença da praga nos referidos meses. Resultados semelhantes foram encontrados por Figueredo (2002), em estudos na Venezuela, o autor observou que os menores níveis populacionais da mosca-negra-dos-citros ocorreram também durante a época de maior precipitação na área experimental.

Flanders (1969), em trabalho realizado no México, observou que ventos fortes e chuvas pesadas mostraram-se capazes de desalojar e matar adultos da mosca-negra-dos-citros. Mesmo resultado encontrado por Medeiros et al. (2009), estudando em condições de campo a dinâmica populacional da mosca negra em Citrus spp. No município de São Luís - MA, observaram que no período chuvoso houve redução no número de posturas, ovos, e ninfas nas áreas experimentais. Da mesma forma, Menezes et al. (2008) observaram que chuvas intensas 
podem funcionar como importante fator de mortalidade de adultos de mosca-negra na cultura de citros, o que provavelmente afetaria o desenvolvimento das fases de ovo e ninfa. Maia (2008), estudando a distribuição da mosca-negra-dos-citros a fim de determinar um plano de amostragem sequencial observou que a diminuição da população está relacionada ao fato de que chuvas intensas podem ser fatores importantes de mortalidade de adultos, além da alta proliferação de microorganismos que favorece o controle microbiano desse inseto.

Para os meses de abril e maio observou-se índice elevado de plantas com presença de mosca negra, logo após um período intenso de chuvas (janeiro, fevereiro e março) (Figura 1), esse aumento de plantas infestadas está relacionado a um maior crescimento vegetativo das plantas de citros que se da nesse período de maior precipitação na região norte do país, e por essa fase ser a preferida para alimentação e oviposição de A. woglumi.

\section{CONCLUSÃO}

A área experimental mostrou-se infestada durante todas as avaliações.

A temperatura média mensal $\left({ }^{\circ} \mathrm{C}\right)$ influenciou na regulação da população de $A$. woglumi.

Chuvas intensas reduziram a infestação de A. woglumi.

\section{REFERÊNCIAS}

BATALDEN, R.V. et al. Ecological niches in sequential generations of eastern North American Monarch Butterflies (Lepidoptera: Danaidae): The Ecology of Migration and Likely Climate Change Implications. Environ. Entomol., 36: 1365 - 1373, 2007.

CUNHA, M.L.A. Distribuição, hospedeiros, densidade populacional, aspectos biológicos e controle químico da mosca negra dos citros (Aleurocanthus woglumi Ashby) nas condições do Estado do Pará. 54f. 2003. Dissertação (Mestrado em Agronomia) Universidade Federal Rural da Amazônia, Belém.

DELGADO, A. Control biológico de la mosca prieta de los cítricos en la república. Fitolito. v.2, n.5, p. 1-16, 1943.

EPPO - European and mediterranean plant protection organization. Aleurocanthus woglumi. In: __. Quarantine Pests for Europe, 2.ed, Wallingford: CAB International, 1997.p.25-29.

FIGUEREDO, L.C. Manejo fitossanitario de la mosca prieta de los citricos (Aleurocanthus woglumi Ashby) en las condiciones de la empresa de citricos sola. $63 \mathrm{f}$. 2002. Dissertação (Maestría en Fruticultura Tropical) - Instituto de Investigaciones de Fruticultura tropical, La Havana.

FLANDERS, S.E. Observations on citrus blackfly parasites in índia and México and correlated circunstances. Can. Entomol. v.101, n. 467 - 480, 1969. 
IBGE - Instituto Brasileiro de Geografia e Estatística. Estados, lavoura permanente; Disponível em: < http://www.ibge.gov.br/estadosat/temas.php?sigla=pa\&tema=lavourapermanente 2009 >. Acesso em: 17 out. 2009.

MAIA, P.S.P. Caracterização da distribuição espacial da mosca negra dos citros (Aleurocanthus woglumi Ashby, 1915) em pomar georreferenciado para determinar um plano de amostragem sequencial. 77f. 2008. Dissertação (Mestrado); Universidade Federal Rural da Amazônia, Belém.

MAPA - Ministério da Agricultura, Pecuária e Abastecimento. Lista de pragas quarentenárias presentes - (A2); Disponível em: < http://extranet.agricultura.gov.br/sislegisconsulta/consultarLegislacao.do?operacao=visualizar\&id=18212 >. Acesso em: 23 dez. 2009.

MEDEIROS, F.R. et al. Dinâmica populacional da mosca-negra-dos-citros Aleurocanthus woglumi ashby (hemiptera: aleyrodidae) em Citrus spp. no município de São Luís - MA. Rev. Bras. Frutic., v.31, p. 1016 - 1021, 2009.

MENEZES, R.O. et al. Amostragem sequencial com base na lei de Taylor para levantamento populacional da mosca-negra-doscitros (Aleurocanthus woglumi Ashby) em pomares de citros no município de Capitão Poço-PA. In: SEMINÁRIO DE INICIAÇÃO CIENTIFICA DA UFRA, 6., SEMINÁRIO DE INICIAÇÃO CIENTIFICA DA EMBRATA AMAZÔNICA ORIENTAL, 6., 2008, Belém. Anais... Bélem: UFRA/EMPRAPA AMAZÔNIA ORIENTAL. 2008; Disponível em: 〈http://anaispibic2008.cpatu.embrapa.br/index2.html>. Acesso em: 16 out. 2009.

OLIVEIRA, M.R.V. et al. Mosca negra dos citros Aleurocanthus woglumi: alerta quarentenário. Brasília: Ministério da Agricultura, Pecuária e Abastecimento, 2001, 12p.

PARKINSON, K.; J. SEALES, Citrus blackfly, its presence and management in Trinidad and Tobago. Procaribe News, Network, 2000, 11p.

PENA, M.R. et al. Ocorrência da mosca-negra-dos-citros, Aleurocanthus woglumi Ashby (Hemiptera: Aleyrodidae) no estado de São Paulo. Rev. bras. eng. agríc. ambient., v.83, p. $61-65,2008$.

ROSSATO, V. Ocorrência de Parasitóides de Aleurocanthus woglumi Ashby, 1903 (Hemiptera: Aleyrodidae) e seu Parasitismo por Cales noacki Howard, 1907 (Hymenoptera: Aphelinidae) nos Municípios de Belém, Capitão Poço e Irituia no Estado do Pará. 2007. 39 f. Dissertação (Mestrado): Universidade Federal Rural da Amazônia, Belém.

SILVA, A.B. Mosca negra dos citros, Aleurocanthus woglumi Ashby, praga potencial para a citricultura brasileira. In: POLTRONIERI, L.S.; TRINDADE, D.R.; SANTOS, I.P. Pragas e doenças de cultivos amazônicos. Belém: Embrapa Amazônia Ocidental, 2005. p. 147 - 156.

STATSOFT. Inc. STATISTICA: data analysis software system. Version 7.0. 2004; Disponível em:< http://www.statsoft.com/\# >; Acesso em: 18 set. 2009.

TRNKAA, M. et al. European corn borer life stage model: Regional estimates of pest development and spatial distribution under present and future climate. Ecol. Model. v. 207, p. $61-84,2007$. 